Article

\title{
Highly Unsaturated Binuclear Butadiene Iron Carbonyls: Quintet Spin States, Perpendicular Structures, Agostic Hydrogen Atoms, and Iron-Iron Multiple Bonds
}

\section{Yi Zeng ${ }^{1}$, Shijian Wang ${ }^{1}$, Hao Feng ${ }^{1, *}$, Yaoming Xie ${ }^{2}$ and R. Bruce King ${ }^{2, *}$}

1 School of Physics and Chemistry, Research Center for Advanced Computation, Xihua University, Chengdu, China; E-Mails: zengyi08@ hotmail.com (Y.Z.); xhuwsj@163.com (S.W.)

2 Department of Chemistry and Center for Computational Chemistry; University of Georgia, Athens, GA 30602, USA; E-Mail: ymxie1@yahoo.com

* Authors to whom correspondence should be addressed; E-Mails: fenghao@ mail.xhu.edu.cn (H.F.); rbking@ chem.uga.edu (R.B.K.); Tel.: +86-28-87727663 (H.F.); +1-706-542-1901 (R.B.K.); Fax: +1-706-542-9454 (R.B.K.).

Received: 22 February 2011; in revised form: 8 March 2011 / Accepted: 14 March 2011 / Published: 30 March 2011

\begin{abstract}
The highly unsaturated binuclear butadiene iron carbonyls $\left(\mathrm{C}_{4} \mathrm{H}_{6}\right)_{2} \mathrm{Fe}_{2}(\mathrm{CO})_{n}$ $(n=2,1)$ have been examined using density functional theory. For $\left(\mathrm{C}_{4} \mathrm{H}_{6}\right)_{2} \mathrm{Fe}_{2}(\mathrm{CO})_{n}(n=2,1)$, both coaxial and perpendicular structures are found. The global minima of $\left(\mathrm{C}_{4} \mathrm{H}_{6}\right)_{2} \mathrm{Fe}_{2}(\mathrm{CO})_{n}(n=2,1)$ are the perpendicular structures $\mathbf{2 Q - 1}$ and $\mathbf{1 Q - 1}$, respectively, with 17- and 15-electron configurations for the iron atoms leading to quintet spin states. The $\mathrm{Fe}=\mathrm{Fe}$ distance of $2.361 \AA(\mathrm{M} 06-\mathrm{L})$ in the $\left(\mathrm{C}_{4} \mathrm{H}_{6}\right)_{2} \mathrm{Fe}_{2}(\mathrm{CO})_{2}$ structure 2Q-1 suggests a formal double bond. The $\mathrm{Fe} \equiv \mathrm{Fe}$ bond distance in the $\left(\mathrm{C}_{4} \mathrm{H}_{6}\right)_{2} \mathrm{Fe}_{2}(\mathrm{CO})$ structure 1Q-1 is even shorter at $2.273 \AA$ (M06-L), suggesting a triple bond. Higher energy $\left(\mathrm{C}_{4} \mathrm{H}_{6}\right)_{2} \mathrm{Fe}_{2}(\mathrm{CO})_{n}$ $(n=2,1)$ structures include structures in which a bridging butadiene ligand is bonded to one of the iron atoms as a tetrahapto ligand and to the other iron atom through two agostic hydrogen atoms from the end $\mathrm{CH}_{2}$ groups. Singlet $\left(\mathrm{C}_{4} \mathrm{H}_{6}\right)_{2} \mathrm{Fe}_{2}(\mathrm{CO})$ structures with formal $\mathrm{Fe}-\mathrm{Fe}$ quadruple bonds of lengths $\sim 2.05 \AA$ were also found but at very high energies $(\sim 47 \mathrm{kcal} / \mathrm{mol})$ relative to the global minimum.
\end{abstract}

Keywords: iron carbonyls; iron-iron bonding; agostic hydrogen atom; metal-olefin complexes 


\section{Introduction}

The chemistry of metal carbonyl complexes of acyclic hydrocarbons dates back to the 1930 discovery by Reihlen et al. [1] of the mononuclear butadiene iron tricarbonyl complex, $\mathrm{C}_{4} \mathrm{H}_{6} \mathrm{Fe}(\mathrm{CO})_{3}$ by the reaction of butadiene with iron pentacarbonyl at elevated temperatures. The proposed tetrahapto bonding of the butadiene ligand to the $\mathrm{Fe}(\mathrm{CO})_{3}$ unit in this complex was confirmed in 1963 by Mills and Robinson [2] using X-ray crystallography at $-40{ }^{\circ} \mathrm{C}$ (Figure 1A). In addition, in 1962 Murdoch and Weiss [3] used the reaction of butadiene with $\mathrm{Fe}_{2}(\mathrm{CO})_{9}$ at room temperature to synthesize the tetracarbonyl $\left(\eta^{2}-\mathrm{C}_{4} \mathrm{H}_{6}\right) \mathrm{Fe}(\mathrm{CO})_{4}$ in which only one of the two $\mathrm{C}=\mathrm{C}$ double bonds of the butadiene ligand is bonded to the iron atom. An additional product from the latter reaction was the binuclear complex $\mathrm{C}_{4} \mathrm{H}_{6}\left[\mathrm{Fe}(\mathrm{CO})_{4}\right]_{2}$ in which each $\mathrm{C}=\mathrm{C}$ double bond of the butadiene ligand is bonded to a separate $\mathrm{Fe}(\mathrm{CO})_{4}$ unit with the iron atoms much too far apart for any kind of direct iron-iron bond. However, no binuclear butadiene iron carbonyl derivatives with short iron-iron distances suggesting iron-iron bonds have been synthesized. In order to assess the possibilities for binuclear iron carbonyl derivatives with iron-iron bonds we have performed a density functional theory (DFT) study on possible structures for $\left(\eta^{4}-\mathrm{C}_{4} \mathrm{H}_{6}\right)_{2} \mathrm{Fe}_{2}(\mathrm{CO})_{n}(n=5,4,3)$, predicted to have structures with formal $\mathrm{Fe}-\mathrm{Fe}$ single bonds, $\mathrm{Fe}=\mathrm{Fe}$ double bonds, and $\mathrm{Fe} \equiv \mathrm{Fe}$ triple bonds, respectively [4]. In general, the lowest energy structures for these $\left(\eta^{4}-\mathrm{C}_{4} \mathrm{H}_{6}\right)_{2} \mathrm{Fe}_{2}(\mathrm{CO})_{n}$ derivatives were found to be coaxial structures in which each metal atom is bonded to a single butadiene ligand (Figure 1B).

Figure 1. Structure of $\left(\eta^{4}-\mathrm{C}_{4} \mathrm{H}_{6}\right) \mathrm{Fe}(\mathrm{CO})_{3}(\mathbf{A})$ and two general structure types for binuclear metal carbonyls, coaxial $(\mathbf{B})$ and perpendicular $(\mathbf{C})$.

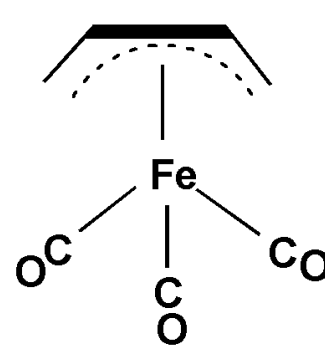

A

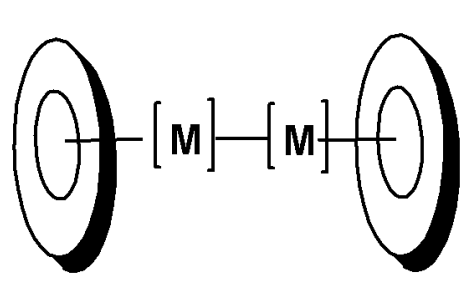

B

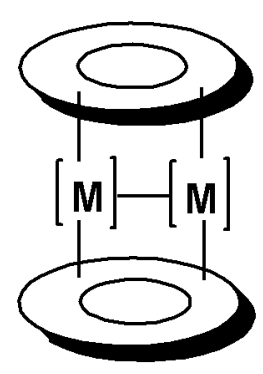

C

This paper reports a DFT study of the still more highly unsaturated $\left(\mathrm{C}_{4} \mathrm{H}_{6}\right)_{2} \mathrm{Fe}_{2}(\mathrm{CO})_{n}(n=2,1)$ derivatives. Such systems are interesting since strict adherence to the 18-electron rule suggests that these highly unsaturated derivatives might provide examples of very short formal iron-iron quadruple and quintuple bonds. However, for such systems containing two or fewer carbonyl groups, alternative perpendicular structures are possible in which the butadiene ligands bridge the pair of iron atoms (Figure 1C). Structures of both types were found in this work. Quintet spin state structures were found to be the lowest energy structures for both $\left(\mathrm{C}_{4} \mathrm{H}_{6}\right)_{2} \mathrm{Fe}_{2}(\mathrm{CO})_{2}$ and $\left(\mathrm{C}_{4} \mathrm{H}_{6}\right)_{2} \mathrm{Fe}_{2}(\mathrm{CO})$. In addition, interesting structures were found with agostic hydrogen atoms bridging $\mathrm{Fe}-\mathrm{C}$ bonds. 


\section{Theoretical Methods}

Density functional theory (DFT) including electron correlation effects has been shown to be a powerful and effective computational tool in organotransition metal chemistry [5-19]. Three DFT methods were used for this work. The first functional was BP86, which combines Becke's 1988 exchange functional (B) with Perdew's 1986 gradient corrected correlation functional method (P86), and usually provides better vibrational frequencies [20,21]. The second DFT method was B3LYP, which is the hybrid HF/DFT functional using the combination of the three-parameter Becke functional (B3) [22] with the Lee-Yang-Parr (LYP) generalized gradient correlation functional [23]. The third was a hybrid meta-GGA DFT method, M06-L, developed by Truhlar's group [24]. Recently Truhlar's group made much progress to the development of improved exchange-correlation functionals that are essential for expanding the applicability of Kohn-Sham DFT, such as the M06 suite. Thus M06-L was constructed using three strategies: constraint satisfaction, modeling the exchange-correlation hole, and empirical fits. They concluded that M06-L is one of the best functionals for the study of organometallic and inorganic thermochemistry, and is the best functional for transition metal energetics. In comparing the first two DFT methods Reiher and collaborators found that B3LYP always overestimates the energy of high-spin states and BP86 overestimates the energies of low-spin states for a series of the Fe(II)-S complexes [25]. In the present study, we found that the M06-L method predicts an intermediate energy difference, anticipated to be closer to the experimental. We therefore adopt the energy order predicted by the M06-L method, but list the BP86 and B3LYP results in the Supporting Information.

Basis sets have been chosen to provide continuity with a body of existing research on organometallic compounds. Fortunately, DFT methods are far less basis set sensitive than higher-level methods such as coupled cluster theory. In this work, the double- $\zeta$ plus polarization (DZP) basis sets used for $\mathrm{C}$ and $\mathrm{O}$ add one set of pure spherical harmonic $\mathrm{d}$ functions with orbital exponents $\alpha_{\mathrm{d}}(\mathrm{C})=0.75$ and $\alpha_{\mathrm{d}}(\mathrm{O})=0.85$ to the Huzinaga Dunning standard contracted DZ sets and are denoted as $(9 \mathrm{~s} 5 \mathrm{p} 1 \mathrm{~d} / 4 \mathrm{~s} 2 \mathrm{p} 1 \mathrm{~d})$ [26,27]. For $\mathrm{H}$, a set of p polarization functions $\alpha_{\mathrm{p}}(\mathrm{H})=0.75$ is added to the Huzinaga Dunning DZ sets. For Fe, in our loosely contracted DZP basis set, the Wachters' primitive set [28] is used after being augmented by two sets of $\mathrm{p}$ functions and one set of $\mathrm{d}$ functions and then contracted using the method of Hood, Pitzer, and Schaefer [29]. This basis set is denoted as (14s11p6d/10s8p3d).

The geometries of the structures were fully optimized using the Gaussian09 program [30] with the three selected DFT methods and with the indicated DZP basis set. The vibrational frequencies were determined by evaluating analytically the second derivatives of the energy with respect to the nuclear coordinates at the same levels. The corresponding infrared intensities were also evaluated analytically. The fine grid $(75,302)$ was the default for evaluating integrals numerically, and the tight designation was the default for the energy convergence, as well as the tight option for the geometry optimizations. In some cases, the finer grid $(120,974)$ was used for investigating small imaginary vibrational frequencies. Natural bond orbital (NBO) analyses [31] used the DZP BP86 method with the NBO 3.1 version attached in the Gaussian03 program.

The optimized $\left(\mathrm{C}_{4} \mathrm{H}_{6}\right)_{2} \mathrm{Fe}_{2}(\mathrm{CO})_{n}(n=2,1)$ structures are depicted in Figures 2 to 7 . In these figures, the upper and lower distances were obtained by the M06-L and BP86 method, respectively. The 
structures are designated as $\mathbf{n X}-\mathbf{m}$, where $\mathbf{n}$ stands for the number of $\mathrm{CO}$ groups, $\mathbf{X}$ designates the spin state using $\mathbf{S}$ for singlets, $\mathbf{T}$ for triplets and $\mathbf{Q}$ for quintets, and $\mathbf{m}$ orders the structures according to their relative energies. Note that, although the singlets, the triplets and the quintets are discussed in separate sections, the relative energies are considered together on the basis of the number of carbonyls. The M06-L method appears to predict the better singlet-triplet splittings.

The relative energies corrected for zero-point energies are listed in the Supporting Information, where computed enthalpies and free energies are also given. These relative free energies agree within $2 \mathrm{kcal} / \mathrm{mol}$ with the relative electronic energies.

\section{Results and Discussion}

\section{1. $\left(\mathrm{C}_{4} \mathrm{H}_{6}\right)_{2} \mathrm{Fe}_{2}(\mathrm{CO})_{2}$}

Three types of stationary points, namely, coaxial structures, perpendicular structures, and deformed coaxial structures, have been found for $\left(\mathrm{C}_{4} \mathrm{H}_{6}\right)_{2} \mathrm{Fe}_{2}(\mathrm{CO})_{2}$. The global minimum of the $\left(\mathrm{C}_{4} \mathrm{H}_{6}\right)_{2} \mathrm{Fe}_{2}(\mathrm{CO})_{2}$ is the quintet structure 2Q-1 according to the relative energies listed in Tables 1, 2, and 3.

\subsubsection{Quintet $\left(\mathrm{C}_{4} \mathrm{H}_{6}\right)_{2} \mathrm{Fe}_{2}(\mathrm{CO})_{2}$ Structures}

Three quintet structures were found for $\left(\mathrm{C}_{4} \mathrm{H}_{6}\right)_{2} \mathrm{Fe}_{2}(\mathrm{CO})_{2}$ (Figure 2 and Table 1). The perpendicular structure 2Q-1 with a bridging $\mathrm{CO}$ group and two bridging butadiene ligands is the global minimum. The $\mathrm{Fe}=\mathrm{Fe}$ distance in $\mathbf{2 Q - 1}$ is predicted by M06-L to be $2.361 \AA$. This can be interpreted as a formal $\mathrm{Fe}=\mathrm{Fe}$ double bond to give one iron atom a 17-electron configuration and the other iron atom a 15-electron configuration. This can correspond to a quintet spin state.

Figure 2. Quintet structures for $\left(\mathrm{C}_{4} \mathrm{H}_{6}\right)_{2} \mathrm{Fe}_{2}(\mathrm{CO})_{2}$. The upper bond distances were obtained by the M06-L method and the lower bond distances by the BP86 method.

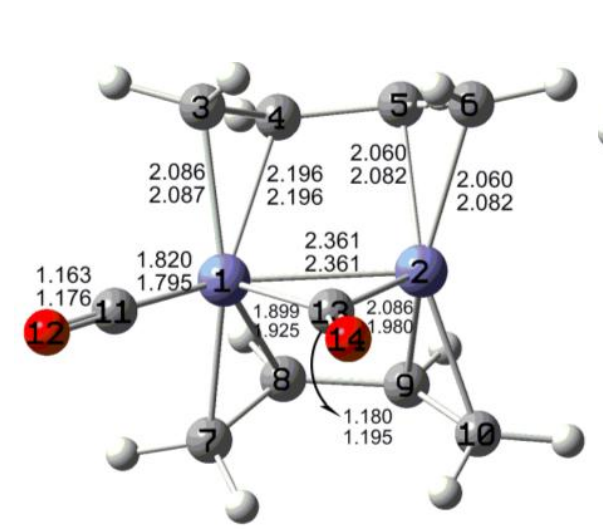

2Q-1, $C_{s}$

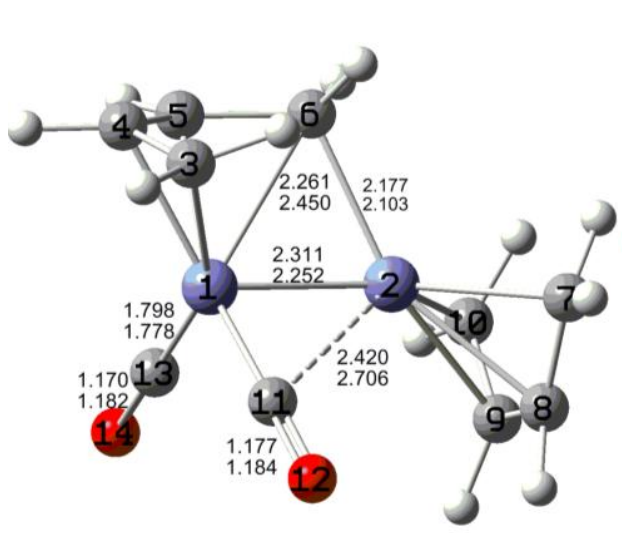

$2 Q-2, C_{1}$

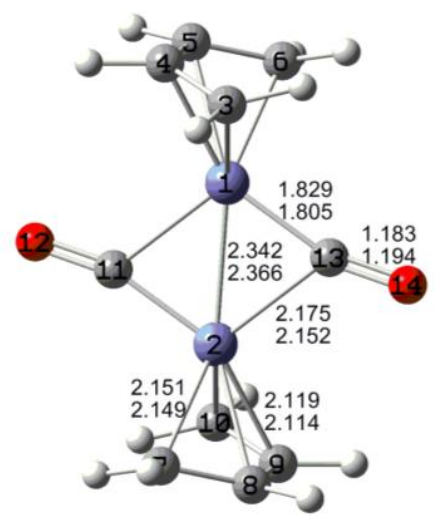

$2 Q-3, C_{2 h}$ 
Table 1. Fe-Fe distances ( $)$, HOMO-LUMO energies ( $E$, in hartree), HOMO-LUMO gaps (in $\mathrm{eV})$, total energies $(E$, in hartree), relative energies $(\Delta E$, in $\mathrm{kcal} / \mathrm{mol}$, numbers of imaginary frequencies (Nimag) and spin expectation values $\left\langle S^{2}\right\rangle$ for the quintet $\left(\mathrm{C}_{4} \mathrm{H}_{6}\right)_{2} \mathrm{Fe}_{2}(\mathrm{CO})_{2}$ structures with the M06-L method.

\begin{tabular}{clccc}
\hline & $\mathbf{2 Q - 1}\left(C_{s}\right)$ & $\mathbf{2 Q - 2}\left(C_{1}\right)$ & $\mathbf{2 Q - 3}\left(C_{2 h}\right)$ \\
\hline M06-L & Fe-Fe & 2.361 & 2.311 & 2.342 \\
& HOMO $(\alpha)$ & -0.17183 & -0.17530 & -0.17208 \\
& LUMO $(\alpha)$ & -0.09384 & -0.10290 & -0.11149 \\
gap/eV & 2.12 & 1.97 & 1.65 \\
$E$ & -3066.14608 & -3066.14371 & -3066.13340 \\
$\Delta E$ & 0.0 & 1.5 & 8.0 \\
Nimag & none & none & none \\
$\left\langle S^{2}\right\rangle$ & 6.30 & 6.31 & 6.63 \\
\hline
\end{tabular}

A deformed coaxial $\left(\mathrm{C}_{4} \mathrm{H}_{6}\right)_{2} \mathrm{Fe}_{2}(\mathrm{CO})_{2}$ structure 2Q-2 with one terminal $\mathrm{CO}$ group, one semibridging carbonyl group, and one bridging butadiene ligand is predicted to lie only $1.5 \mathrm{kcal} / \mathrm{mol}$ (M06-L) in energy above the global minimum 2Q-1 (Figure 2 and Table 1). The bridging butadiene ligand in 2Q-2 is bonded as a trihapto ligand to one iron atom and as a monohapto ligand to the other iron atom. The $\mathrm{Fe}=\mathrm{Fe}$ bond distance in $\mathbf{2 Q - 2}$ of $2.311 \AA$ (M06-L) is close to that in $\mathbf{2 Q - 1}$ and can likewise be interpreted as a formal double bond. Again this gives one iron atom a 15-electron configuration and the other iron atom a 17-electron configuration, which can correspond to a quintet spin state.

The coaxial $\left(\mathrm{C}_{4} \mathrm{H}_{6}\right)_{2} \mathrm{Fe}_{2}(\mathrm{CO})_{2}$ structure 2Q-3 has two bridging carbonyl groups and lies $8.0 \mathrm{kcal} / \mathrm{mol}$ in energy above 2Q-1. The $\mathrm{Fe}=\mathrm{Fe}$ bond distance in $\mathbf{2 Q - 3}$ is $2.342 \AA$ (M06-L), which is similar to those in 2Q-1 and 2Q-2 and thus can correspond to a formal double bond. This gives each iron atom in 2Q-3 a 16-electron configuration, which can correspond to a quintet spin state.

\subsubsection{Triplet $\left(\mathrm{C}_{4} \mathrm{H}_{6}\right)_{2} \mathrm{Fe}_{2}(\mathrm{CO})_{2}$ Structures}

Three triplet structures were found for $\left(\mathrm{C}_{4} \mathrm{H}_{6}\right)_{2} \mathrm{Fe}_{2}(\mathrm{CO})_{2}$ (Figure 3 and Table 2). The lowest energy of these triplet structures, namely $\mathbf{2 T - 1}$ lying $6.8 \mathrm{kcal} / \mathrm{mol}$ in energy above the quintet global minimum 2Q-1, is a coaxial structure with two bridging carbonyl groups and two terminal butadiene ligands. The $\mathrm{Fe}=\mathrm{Fe}$ bond distance of $2.209 \AA$ (M06-L) in 2T-1 is $\sim 0.1 \AA$ shorter than that in the similar quintet spin state structure 2Q-3 and thus can be interpreted as a formal triple bond. This gives each iron atom in 2T-1 a 17-electron configuration consistent with a binuclear triplet.

The next triplet $\left(\mathrm{C}_{4} \mathrm{H}_{6}\right)_{2} \mathrm{Fe}_{2}(\mathrm{CO})_{2}$ structure, namely $\mathbf{2 T - 2}$, lying $8.4 \mathrm{kcal} / \mathrm{mol}$ above the quintet global minimum 2Q-1, is a deformed coaxial structure with one bridging butadiene ligand, one terminal butadiene ligand, and two terminal carbonyl groups (Figure 3 and Table 2). The bridging butadiene ligand in 2T-2 is bonded to one of the iron atoms as a tetrahapto ligand. In addition, the two terminal hydrogen atoms of this butadiene ligand are agostic hydrogen atoms bonding to the other iron atom through $\mathrm{C}-\mathrm{H}-\mathrm{Fe}$ bridging units with $\mathrm{Fe}-\mathrm{C}$ distances of $\sim 2.2 \AA$ and $\mathrm{Fe}-\mathrm{H}$ distances of $\sim 1.9 \AA$. These $\mathrm{C}-\mathrm{H}-\mathrm{Fe}$ units are predicted to exhibit abnormally low $v(\mathrm{C}-\mathrm{H})$ frequencies of 2515 and $2561 \mathrm{~cm}^{-1}$. The Fe-Fe distance in $\mathbf{2 T - 2}$ is relatively long at $2.433 \AA$ (M06-L) and can thus be 
considered as a formal single bond. This gives each iron atom in 2T-2 the 17-electron configuration for a binuclear triplet.

Figure 3. Triplet structures for $\left(\mathrm{C}_{4} \mathrm{H}_{6}\right)_{2} \mathrm{Fe}_{2}(\mathrm{CO})_{2}$. The upper bond distances were obtained by the M06-L method and the lower bond distances by the BP86 method.

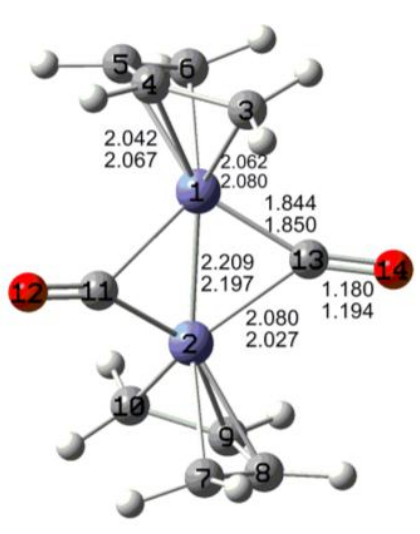

$2 \mathrm{~T}-1, C_{2}$

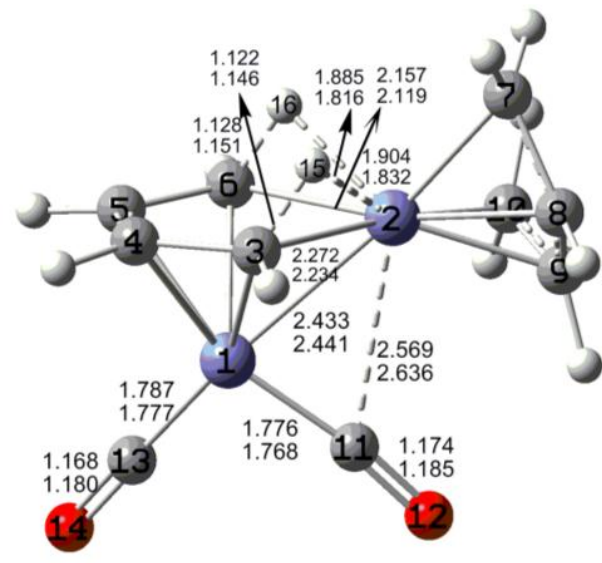

$2 \mathrm{~T}-2, C_{1}$

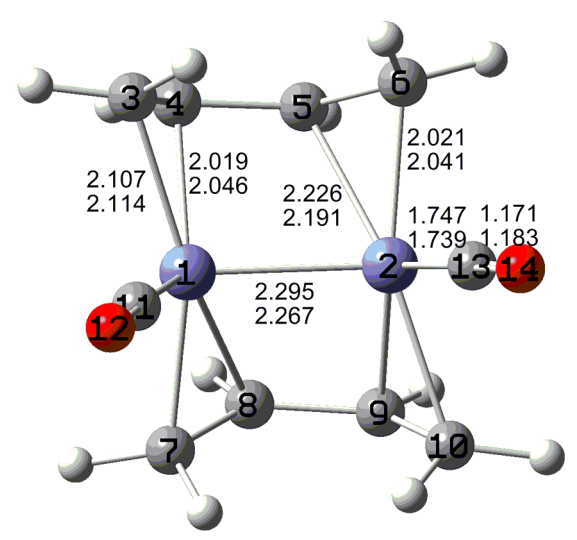

$2 \mathrm{~T}-3, C_{2}$

Table 2. Fe-Fe distances ( $)$, HOMO-LUMO energies ( $E$, in hartree), HOMO-LUMO gaps (in $\mathrm{eV}$ ), total energies ( $E$, in hartree), relative energies $(\Delta E$, in $\mathrm{kcal} / \mathrm{mol})$, numbers of imaginary frequencies (Nimag) and spin expectation values $\left\langle S^{2}\right\rangle$ for the triplet $\left(\mathrm{C}_{4} \mathrm{H}_{6}\right)_{2} \mathrm{Fe}_{2}(\mathrm{CO})_{2}$ structures with the M06-L method.

\begin{tabular}{clccc}
\hline & & 2T-1 $\left(C_{2}\right)$ & 2T-2 $\left(C_{1}\right)$ & 2T-3 $\left(C_{2}\right)$ \\
\hline M06-L & Fe-Fe & 2.209 & 2.433 & 2.295 \\
& $\operatorname{HOMO}(\alpha)$ & -0.19453 & -0.17557 & -0.15910 \\
& $\operatorname{LUMO}(\alpha)$ & -0.12453 & -0.10739 & -0.10465 \\
gap/eV & 1.90 & 1.86 & 1.48 \\
$E$ & -3066.13525 & -3066.13271 & -3066.1265 \\
$\Delta E$ & 6.8 & 8.4 & 12.3 \\
Nimag & none & none & none \\
$\left\langle S^{2}\right\rangle$ & 2.20 & 2.12 & 2.21 \\
\hline
\end{tabular}

The perpendicular triplet $\left(\mathrm{C}_{4} \mathrm{H}_{6}\right)_{2} \mathrm{Fe}_{2}(\mathrm{CO})_{2}$ structure 2T-3 has two bridging butadiene ligands and two terminal carbonyl groups and lies $12.3 \mathrm{kcal} / \mathrm{mol}$ (M06-L) in energy above the global minimum 2Q-1 (Figure 3 and Table 2). The $\mathrm{Fe} \equiv \mathrm{Fe}$ distance of $2.295 \AA$ (M06-L) in 2T-3 can correspond to a formal triple bond to give each iron atom a 17-electron configuration for a binuclear triplet.

\subsubsection{Singlet $\left(\mathrm{C}_{4} \mathrm{H}_{6}\right)_{2} \mathrm{Fe}_{2}(\mathrm{CO})_{2}$ Structures}

Three distinct singlet structures are obtained for $\left(\mathrm{C}_{4} \mathrm{H}_{6}\right)_{2} \mathrm{Fe}_{2}(\mathrm{CO})_{2}$. However, they are all high energy structures lying from 19 to $30 \mathrm{kcal} / \mathrm{mol}$ above the 2Q-1 global minimum (Figure 4 and Table 3). The lowest energy singlet $\left(\mathrm{C}_{4} \mathrm{H}_{6}\right)_{2} \mathrm{Fe}_{2}(\mathrm{CO})_{2}$ structure $\mathbf{2 S - 1}$, lying $19.1 \mathrm{kcal} / \mathrm{mol}$ above 2Q-1, is very similar to the triplet structure 2T-2. Thus structure 2S-1 has a bridging butadiene ligand connected to one iron atom as a tetrahapto ligand and to the other atom through two non-equivalent $\mathrm{C}-\mathrm{H}-\mathrm{Fe}$ bridges with $\mathrm{Fe}-\mathrm{C}$ distances of 2.166 and $2.431 \AA$ and $\mathrm{Fe}-\mathrm{H}$ distances of 1.844 and $2.113 \AA$ (M06-L). The 
strikingly lower $v(\mathrm{C}-\mathrm{H})$ vibrational frequencies $2392 \mathrm{~cm}^{-1}$ and $2912 \mathrm{~cm}^{-1}$ (BP86) and the longer C-H bond distances involving these agostic hydrogens confirm the weaker $\mathrm{C}-\mathrm{H}$ bonds. One of the carbonyl groups in 2S-1 is a nearly symmetrical bridging carbonyl group with $\mathrm{Fe}-\mathrm{C}$ distances of 1.878 and $1.948 \AA$ (M06-L). The remaining carbonyl group and butadiene ligand in $\mathbf{2 S - 1}$ are both terminal groups. The predicted $\mathrm{Fe}=\mathrm{Fe}$ bond length of $2.344 \AA$ (M06-L) in $\mathbf{2 S - 1}$ is $\sim 0.1 \AA$ longer than the formal $\mathrm{Fe}-\mathrm{Fe}$ single bond in $\mathbf{2 T - 2}$ and thus can be considered to be a formal double bond, thereby giving both iron atoms the favored 18-electron configuration in 2S-1.

The $C_{2 h}$ coaxial singlet $\left(\mathrm{C}_{4} \mathrm{H}_{6}\right)_{2} \mathrm{Fe}_{2}(\mathrm{CO})_{2}$ structure $2 \mathrm{~S}-2$ with two bridging carbonyl groups and terminal butadiene ligands is predicted to lie $23.9 \mathrm{kcal} / \mathrm{mol}$ (M06-L) in energy above the global minimum 2Q-1 (Figure 4 and Table 3). The Fe=Fe bond distance of $2.327 \AA$ (M06-L) in 2S-2 is similar to that in $\mathbf{2 S - 1}$ and thus can be assigned to a formal double bond. This gives each iron atom in 2S-2 a 16-electron configuration, which can relate to a binuclear singlet.

Figure 4. Singlet structures for $\left(\mathrm{C}_{4} \mathrm{H}_{6}\right)_{2} \mathrm{Fe}_{2}(\mathrm{CO})_{2}$. The upper bond distances were obtained by the M06-L method and the lower bond distances by the BP86 method.

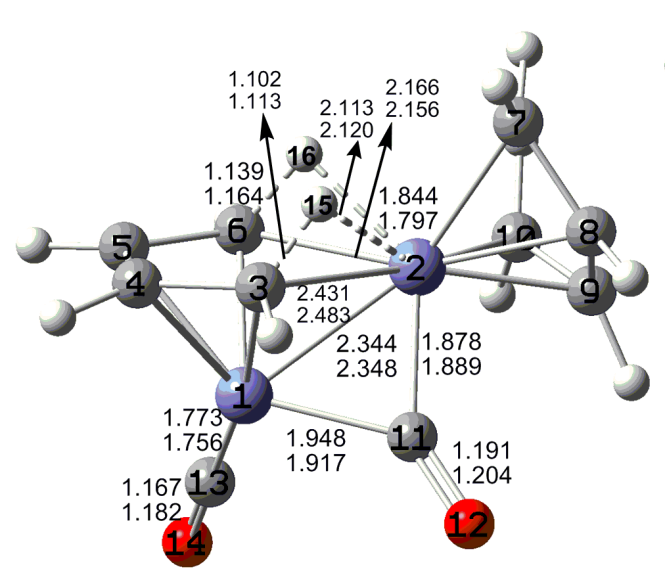

2S-1, $C_{1}$

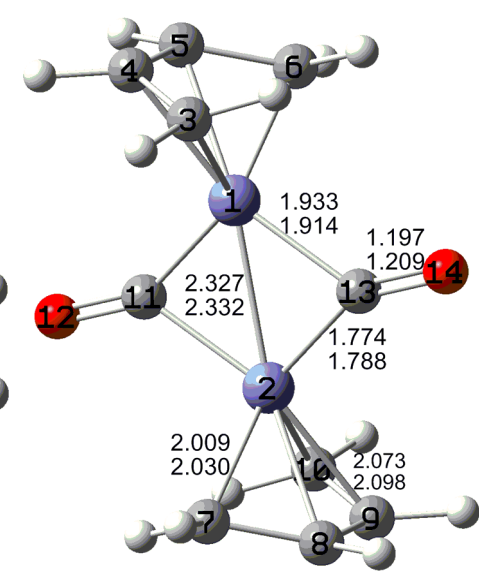

$2 S-2, C_{2 h}$

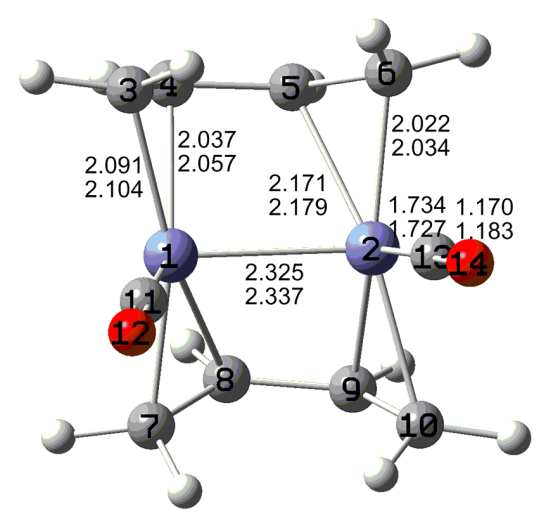

2S-3, $C_{2}$

The $C_{2}$ singlet $\left(\mathrm{C}_{4} \mathrm{H}_{6}\right)_{2} \mathrm{Fe}_{2}(\mathrm{CO})_{2}$ structure $\mathbf{2 S - 3}$ is a perpendicular structure lying $30.0 \mathrm{kcal} / \mathrm{mol}$ (M06-L) above the 2Q-1 global minimum (Figure 4 and Table 3). Both butadiene ligands in 2S-3 are bridging ligands and both carbonyl ligands in $\mathbf{2 S - 3}$ are terminal ligands. The $\mathrm{Fe}=\mathrm{Fe}$ distance of $2.325 \AA$ in $\mathbf{2 S - 3}$ is similar to those in $\mathbf{2 S - 1}$ and $\mathbf{2 S - 2}$ and likewise can correspond to a formal double bond. This gives each iron atom in $\mathbf{2 S - 3}$ a 16-electron configuration suggesting a vacant coordination site on each iron atom. This is consistent with the geometry of the carbonyl groups in $\mathbf{2 S - 3}$.

The overall energy order for $\left(\mathrm{C}_{4} \mathrm{H}_{6}\right)_{2} \mathrm{Fe}_{2}(\mathrm{CO})_{2}$ structures investigated in this section is $\mathbf{2 Q - 1}<\mathbf{2 Q - 2}$ $<2$ T-1 $<2 \mathrm{Q}-3 \sim 2 \mathrm{~T}-2<2 \mathrm{~T}-3<2 \mathrm{~S}-1<2 \mathrm{~S}-2<2 \mathrm{~S}-3$ by M06-L. This suggests that $\left(\mathrm{C}_{4} \mathrm{H}_{6}\right)_{2} \mathrm{Fe}_{2}(\mathrm{CO})_{2}$ prefers high spin state structures. The energy gaps between the HOMOs and LUMOs in Tables 1, 2 and 3 for $\mathbf{2 S - 1} \rightarrow \mathbf{2 T - 2} \rightarrow \mathbf{2 Q - 2}$ are $1.01,1.86$ and $1.97 \mathrm{eV}$, respectively, which increase monotonically with the increase of the spin multiplicity. The same trend is also found for $\mathbf{2 S - 2} \rightarrow \mathbf{2 T - 1}$ $\rightarrow$ 2Q-3 and 2S-3 $\rightarrow$ 2T-3 $\rightarrow$ 2Q-1. 
Table 3. Fe-Fe distances ( $)$, HOMO-LUMO energies ( $E$, in hartree), HOMO-LUMO gaps (in $\mathrm{eV})$, total energies $(E$, in hartree), relative energies $(\Delta E$, in $\mathrm{kcal} / \mathrm{mol})$ and numbers of imaginary frequencies (Nimag) for the singlet $\left(\mathrm{C}_{4} \mathrm{H}_{6}\right)_{2} \mathrm{Fe}_{2}(\mathrm{CO})_{2}$ structures with the M06-L method.

\begin{tabular}{clccc}
\hline & & $\mathbf{2 S - 1}\left(C_{1}\right)$ & $\mathbf{2 S - 2}\left(C_{2 h}\right)$ & $\mathbf{2 S - 3}\left(C_{2}\right)$ \\
\hline M06-L & Fe-Fe & 2.344 & 2.327 & 2.325 \\
& HOMO & -0.15788 & -0.17415 & -0.13105 \\
& LUMO & -0.12068 & -0.13219 & -0.11009 \\
gap/eV & 1.01 & 1.14 & 0.57 \\
E & -3066.11570 & -3066.10797 & -3066.09822 \\
& $\Delta E$ & 19.1 & 23.9 & 30.0 \\
Nimag & none & none & none \\
\hline
\end{tabular}

3.2. $\left(\mathrm{C}_{4} \mathrm{H}_{6}\right)_{2} \mathrm{Fe}_{2}(\mathrm{CO})$

Two types of stationary points for $\left(\mathrm{C}_{4} \mathrm{H}_{6}\right)_{2} \mathrm{Fe}_{2}(\mathrm{CO})$, namely, coaxial and perpendicular structures, are shown in Figures 5, 6 and 7. The global minimum of the $\left(\mathrm{C}_{4} \mathrm{H}_{6}\right)_{2} \mathrm{Fe}_{2}(\mathrm{CO})$ is the quintet structure 1Q-1 according to the relative energies listed in Tables 4,5 , and 6.

\subsubsection{Quintet $\left(\mathrm{C}_{4} \mathrm{H}_{6}\right)_{2} \mathrm{Fe}_{2}(\mathrm{CO})$ Structures}

Two quintet structures were found for $\left(\mathrm{C}_{4} \mathrm{H}_{6}\right)_{2} \mathrm{Fe}_{2}(\mathrm{CO})$ (Figure 5 and Table 4). The perpendicular $\left(\mathrm{C}_{4} \mathrm{H}_{6}\right)_{2} \mathrm{Fe}_{2}(\mathrm{CO})$ global minimum 1Q-1 has two bridging butadiene ligands and a terminal carbonyl group. The $\mathrm{Fe} \equiv \mathrm{Fe}$ distance of $2.273 \AA$ (M06-L) can correspond to a formal triple bond thereby giving the iron atom bearing the carbonyl group a 17-electron configuration but the other iron atom only a 15-electron configuration. This is consistent with a quintet spin multiplicity.

Figure 5. Quintet structures for $\left(\mathrm{C}_{4} \mathrm{H}_{6}\right)_{2} \mathrm{Fe}_{2}(\mathrm{CO})$. The upper bond distances were obtained by the M06-L method and the lower bond distances by the BP86 method.
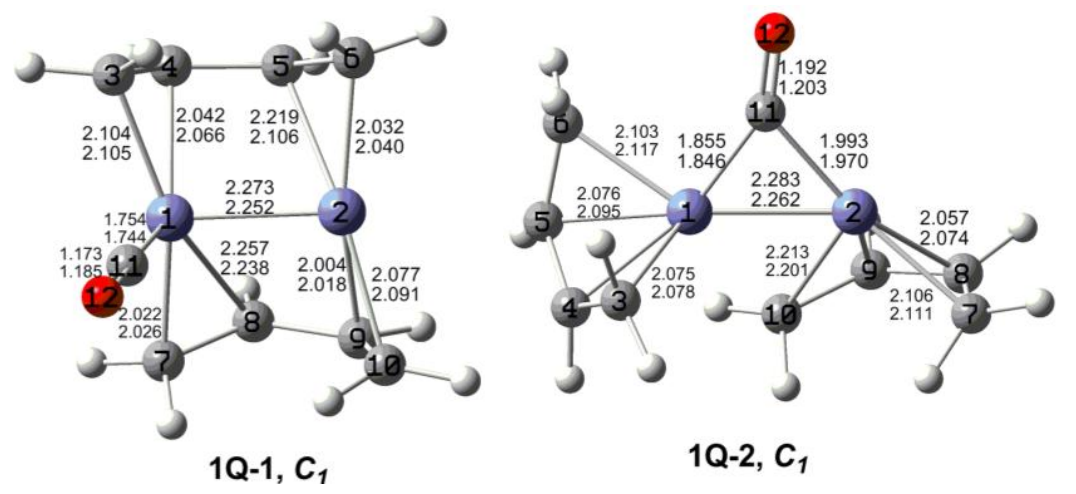

The other quintet $\left(\mathrm{C}_{4} \mathrm{H}_{6}\right)_{2} \mathrm{Fe}_{2}(\mathrm{CO})$ structure 1Q-2 has a bridging $\mathrm{CO}$ group and lies $12.9 \mathrm{kcal} / \mathrm{mol}$ above the global minimum 1Q-1 (Figure 5 and Table 4). The $\mathrm{Fe} \equiv \mathrm{Fe}$ distance of $2.283 \AA$ (M06-L) in 1Q-2 is similar to that in 1Q-1 and likewise can correspond to a formal triple bond. This gives both iron atoms a 16-electron configuration, which can correspond to a binuclear quintet spin state. 
Table 4. Fe-Fe distances ( $)$, HOMO-LUMO energies ( $E$, in hartree), HOMO-LUMO gaps (in eV), total energies $(E$, in hartree), relative energies $(\Delta E$, in $\mathrm{kcal} / \mathrm{mol}$, numbers of imaginary frequencies (Nimag) and spin expectation values $\left\langle S^{2}\right\rangle$ for the quintet $\left(\mathrm{C}_{4} \mathrm{H}_{6}\right)_{2} \mathrm{Fe}_{2}(\mathrm{CO})$ structures with the M06-L method.

\begin{tabular}{llcc}
\hline & & $\mathbf{1 Q - 1}\left(C_{1}\right)$ & $\mathbf{1 Q - 2}\left(C_{1}\right)$ \\
\hline M06-L & Fe-Fe & 2.290 & 2.283 \\
& $\operatorname{HOMO}(\alpha)$ & -0.16350 & -0.17107 \\
& $\operatorname{LUMO}(\alpha)$ & -0.07858 & -0.10795 \\
& $\operatorname{gap} / \mathrm{eV}$ & 2.31 & 1.72 \\
& $E$ & -2952.77563 & -2952.75505 \\
$\Delta E$ & 0.0 & 12.9 \\
& Nimag & none & none \\
& $\left\langle S^{2}\right\rangle$ & 6.32 & 6.40 \\
\hline
\end{tabular}

\subsubsection{Triplet $\left(\mathrm{C}_{4} \mathrm{H}_{6}\right)_{2} \mathrm{Fe}_{2}(\mathrm{CO})$ Structures}

Two triplet $\left(\mathrm{C}_{4} \mathrm{H}_{6}\right)_{2} \mathrm{Fe}_{2}(\mathrm{CO})$ structures were found to lie 12 to $24 \mathrm{kcal} / \mathrm{mol}$ in energy above the quintet global minimum 1Q-1 using the M06-L method (Figure 6 and Table 5). The perpendicular triplet $\left(\mathrm{C}_{4} \mathrm{H}_{6}\right)_{2} \mathrm{Fe}_{2}(\mathrm{CO})$ structure 1T-1, lying $11.6 \mathrm{kcal} / \mathrm{mol}$ above 1Q-1, has two bridging butadiene ligands and a terminal carbonyl group. Considerable spin contamination was found for 1T-1. Thus the spin expectation value $\left\langle S^{2}\right\rangle=2.82$ for 1T-1 as compared with the ideal 2.0. Indeed, a more stable quintet $\left(\mathrm{C}_{4} \mathrm{H}_{6}\right)_{2} \mathrm{Fe}_{2}(\mathrm{CO})$ structure 1Q-1 is found with an $\left\langle S^{2}\right\rangle$ value within $10 \%$ of the ideal 6.0. The $\mathrm{Fe} \equiv \mathrm{Fe}$ distance of $2.291 \AA$ (M06-L) is very similar to the $\mathrm{Fe} \equiv \mathrm{Fe}$ triple bond distances in the quintet structures 1Q-1 and 1Q-2 and thus likewise can correspond to a formal triple bond. This gives the iron atom in 1T-1 bearing the carbonyl group a 17-electron configuration but the other iron atom only a 15-electron configuration. This can correspond to a binuclear triplet with a vacant coordination position on the iron atom with only a 15-electron configuration. The $C_{s}$ coaxial triplet $\left(\mathrm{C}_{4} \mathrm{H}_{6}\right)_{2} \mathrm{Fe}_{2}(\mathrm{CO})$ structure 1T-2, lying $24.2 \mathrm{kcal} / \mathrm{mol}$ (M06-L) above 1Q-1 has a bridging carbonyl group but terminal butadiene ligands. The predicted $\mathrm{Fe} \equiv \mathrm{Fe}$ distance of $2.200 \AA$ (M06-L) is similar to the $\mathrm{Fe} \equiv \mathrm{Fe}$ distances in the other quintet and triplet $\left(\mathrm{C}_{4} \mathrm{H}_{6}\right)_{2} \mathrm{Fe}_{2}(\mathrm{CO})$ structures and likewise can correspond to a formal triple bond. This gives each iron atom in 1T-2 a 16-electron configuration.

Figure 6. Triplet structures for $\left(\mathrm{C}_{4} \mathrm{H}_{6}\right)_{2} \mathrm{Fe}_{2}(\mathrm{CO})$. The upper bond distances were obtained by the M06-L method and the lower bond distances by the BP86 method.
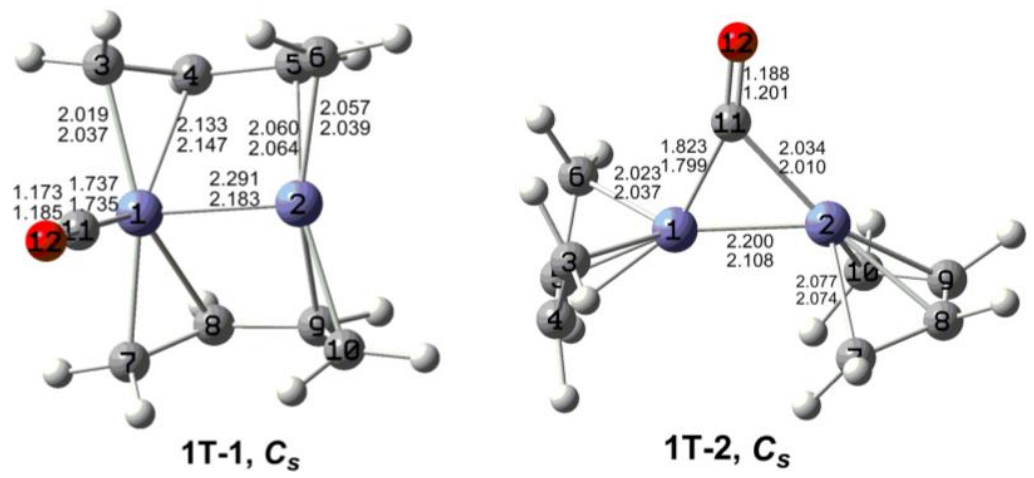


\subsubsection{Singlet $\left(\mathrm{C}_{4} \mathrm{H}_{6}\right)_{2} \mathrm{Fe}_{2}(\mathrm{CO})$ Structures}

Two singlet low-lying $\left(\mathrm{C}_{4} \mathrm{H}_{6}\right)_{2} \mathrm{Fe}_{2}(\mathrm{CO})$ structures were found (Figure 7 and Table 6) but at very high energies relative to the corresponding quintet and triplet structures. Thus the $C_{s}$ perpendicular singlet structure $\mathbf{1 S - 1}$ lies $46.7 \mathrm{kcal} / \mathrm{mol}$ above the quintet global minimum 1Q-1. Structure $\mathbf{1 S - 1}$ has a terminal carbonyl group and bridging butadiene ligands. The Fe-Fe distance in $\mathbf{1 S - 1}$ of $2.051 \AA$ is $\sim 0.2 \AA$ shorter than the $\mathrm{Fe} \equiv \mathrm{Fe}$ distances in the quintet and triplet $\left(\mathrm{C}_{4} \mathrm{H}_{6}\right)_{2} \mathrm{Fe}_{2}(\mathrm{CO})$ structures and thus can correspond to a formal quadruple bond. This gives the iron atom in 1S-1 bearing the carbonyl group the favored 18-electron configuration but the other iron atom only a 16-electron configuration.

Table 5. Fe-Fe distances ( $)$, HOMO-LUMO energies ( $E$, in hartree), HOMO-LUMO gaps (in $\mathrm{eV})$, total energies $(E$, in hartree), relative energies $(\Delta E$, in $\mathrm{kcal} / \mathrm{mol}$, numbers of imaginary frequencies (Nimag) and spin expectation values $\left\langle S^{2}\right\rangle$ for the triplet $\left(\mathrm{C}_{4} \mathrm{H}_{6}\right)_{2} \mathrm{Fe}_{2}(\mathrm{CO})$ structures using the M06-L method.

\begin{tabular}{clcc}
\hline & 1T-1 $\left(C_{s}\right)$ & 1T-2 $\left(C_{s}\right)$ \\
\hline M06-L & Fe-Fe & 2.291 & 2.200 \\
& HOMO $(\alpha)$ & -0.15400 & -0.164149 \\
& LUMO $(\alpha)$ & -0.102794 & -0.093119 \\
gap/eV & 1.39 & 1.93 \\
$E$ & -2952.75716 & -2952.73705 \\
& $\Delta E$ & 11.6 & 24.2 \\
Nimag & none & none \\
& $\left\langle S^{2}\right\rangle$ & 2.82 & 2.22 \\
\hline
\end{tabular}

Figure 7. Singlet structures for $\left(\mathrm{C}_{4} \mathrm{H}_{6}\right)_{2} \mathrm{Fe}_{2}(\mathrm{CO})$. The upper bond distances were obtained by the M06-L method and the lower bond distances by the BP86 method.

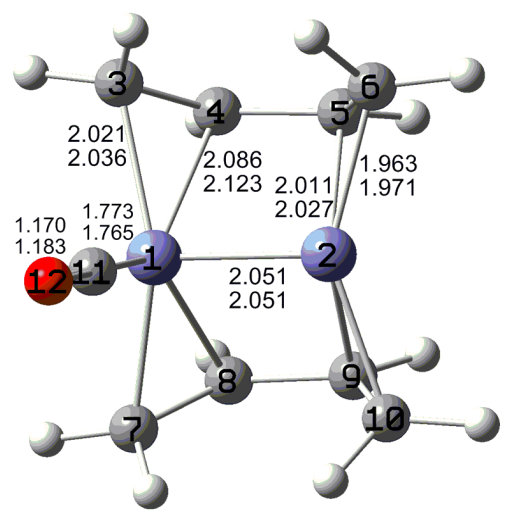

$1 \mathrm{~S}-1, C_{s}$

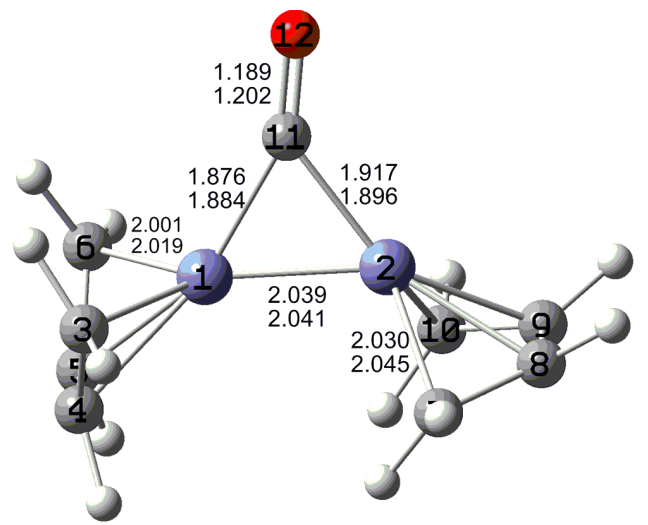

$1 \mathrm{~S}-2, C_{s}$

The $C_{s}$ singlet coaxial $\left(\mathrm{C}_{4} \mathrm{H}_{6}\right)_{2} \mathrm{Fe}_{2}(\mathrm{CO})$ structure $\mathbf{1 S - 2}$ is also a high energy structure, lying $47.4 \mathrm{kcal} / \mathrm{mol}$ above the global minimum 1S-1 (Figure 7 and Table 6). Structure 1S-2 has terminal butadiene ligands and a bridging carbonyl group. The very short Fe-Fe distance of $2.039 \AA$ (M06-L) in 1S-2 is similar to that in 1S-1 and thus likewise can correspond to a formal quadruple bond. This gives one iron atom in 1S-2 the favored 18-electron configuration but the other iron atom only a 16-electron configuration. This asymmetry in the electron count on the iron atoms in $\mathbf{1 S - 2}$ is reflected in a different 
arrangement of the $\eta^{4}$-butadiene ligands on each iron atom. Thus, the "right" iron atom in $\mathbf{1 S - 2}$ as depicted in Figure 7 appears to have a vacant coordination site and thus can correspond to the iron atom with a 16-electron configuration.

Table 6. Fe-Fe distances ( $)$, HOMO-LUMO energies ( $E$, in hartree), HOMO-LUMO gaps (in $\mathrm{eV})$, total energies $(E$, in hartree), relative energies $(\Delta E$, in $\mathrm{kcal} / \mathrm{mol}$, and numbers of imaginary frequencies (Nimag) for the singlet $\left(\mathrm{C}_{4} \mathrm{H}_{6}\right)_{2} \mathrm{Fe}_{2}(\mathrm{CO})$ structures with the M06-L method.

\begin{tabular}{llcc}
\hline & & $\mathbf{1 S - 1}\left(C_{s}\right)$ & $\mathbf{1 S - 2}\left(C_{s}\right)$ \\
\hline M06-L & Fe-Fe & 2.051 & 2.039 \\
& HOMO & -0.12987 & -0.14810 \\
& LUMO & -0.11542 & -0.12583 \\
& gap/eV & 0.39 & 0.61 \\
$E$ & -2952.70120 & -2952.70002 \\
& $\Delta E$ & 46.7 & 47.4 \\
& Nimag & none & none \\
\hline
\end{tabular}

The overall energy order for the $\left(\mathrm{C}_{4} \mathrm{H}_{6}\right)_{2} \mathrm{Fe}_{2}(\mathrm{CO})$ structures investigated in this section is 1Q-1 < 1T-1 < 1Q-2 < 1T-2 < 1S-1 1S-2 (M06-L). Thus the higher spin states are energetically favored. The energy gaps between the HOMOs and LUMOs in Tables 4,5 , and 6 for $\mathbf{1 S - 1} \rightarrow \mathbf{1 T - 1} \rightarrow$ $\mathbf{1 Q - 1}$ are $0.39,1.39$ and $2.31 \mathrm{eV}$, respectively, and that for $\mathbf{1 S - 2} \rightarrow \mathbf{1 T - 2} \rightarrow \mathbf{1 Q - 2}$ are $0.61,1.93$ and $1.72 \mathrm{eV}$, respectively.

\subsection{NBO Analysis}

The natural charges on the iron atoms and the Wiberg Bond Indices (WBIs) for the iron-iron bonds are listed in Table 7 along with the $\mathrm{Fe}-\mathrm{Fe}$ distances, the iron electronic configurations, and formal iron-iron bond orders. For the less unsaturated binuclear butadiene iron carbonyls $\left(\mathrm{C}_{4} \mathrm{H}_{6}\right)_{2} \mathrm{Fe}_{2}(\mathrm{CO})_{n}(n=7,6,5,4,3)$ studied previously [4] the natural charges on the iron atoms correlate mainly with the numbers of carbonyl groups on the iron atoms and the WBIs correlated with the formal iron-iron bond orders. However, the much greater variety of iron electronic configurations and spin states encountered in the highly unsaturated $\left(\mathrm{C}_{4} \mathrm{H}_{6}\right)_{2} \mathrm{Fe}_{2}(\mathrm{CO})_{n}(n=2,1)$ structures reported in this paper make the interpretations much less clear. In this connection, iron atoms bonded to two $\mathrm{CO}$ groups were found to be essentially neutral. In most cases iron atoms bonded to only a single $\mathrm{CO}$ group (or half of two bridging carbonyl groups) have natural positive charges in the range 0.13 to 0.25 . Carbonyl-free iron atoms are even more positive but their natural positive charges span a wide range from 0.28 to 0.83 . Thus the previously observed [4] general trend of increasing natural negative charges on the iron atoms with increasing number of carbonyl ligands is also found here. However, other factors besides the number of carbonyl groups also affect significantly the natural charges on the iron atoms.

The WBIs for the iron-iron bonds in the $\left(\mathrm{C}_{4} \mathrm{H}_{6}\right)_{2} \mathrm{Fe}_{2}(\mathrm{CO})_{n}(n=2,1)$ structures also showed the expected correlation of increased WBI with an increase in formal bond order (Table 7). However, the ranges of WBIs for a given formal iron-iron bond order are relatively broad indicating the significant influence of other factors. The one example of an Fe-Fe single bond in 2T-2 has WBI of 0.19. Most of 
the $\mathrm{Fe}=\mathrm{Fe}$ double bonds have WBIs in the range 0.26 to 0.43 . However, there are some unusually high WBIs for apparent $\mathrm{Fe}=\mathrm{Fe}$ double bonds including 0.59 for the doubly bridged coaxial $\left(\mathrm{C}_{4} \mathrm{H}_{6}\right)_{2} \mathrm{Fe}_{2}(\mathrm{CO})_{2}$ structure 2S-2 and the very high value of 0.93 for the perpendicular $\left(\mathrm{C}_{4} \mathrm{H}_{6}\right)_{2} \mathrm{Fe}_{2}(\mathrm{CO})_{2}$ structure 2S-3. Interpreting the iron-iron bonds in these two structures as formal quadruple bonds would rationalize these significantly higher WBIs and give both iron atoms the favorable 18-electron configurations but would be inconsistent with the iron-iron distances of $\sim 2.3 \AA$. The formal $\mathrm{Fe} \equiv \mathrm{Fe}$ triple bonds in the $\left(\mathrm{C}_{4} \mathrm{H}_{6}\right)_{2} \mathrm{Fe}_{2}(\mathrm{CO})_{n}(n=2,1)$ structures exhibit WBIs in the broad range 0.38 to 0.81 . The two examples of formal $\mathrm{Fe}-\mathrm{Fe}$ quadruple bonds, namely the Fe-Fe bonds in the singlet $\left(\mathrm{C}_{4} \mathrm{H}_{6}\right)_{2} \mathrm{Fe}_{2}(\mathrm{CO})$ structures 1S-1 and 1S-2, exhibit by far the highest WBIs at 1.30 and 1.42, respectively, consistent with the high formal bond orders.

Table 7. Fe-Fe distances, NPA natural charges, iron electron configurations, traditional formal $\mathrm{Fe}-\mathrm{Fe}$ bond orders and Wiberg bond indices (WBIs) for the $\left(\mathrm{C}_{4} \mathrm{H}_{6}\right)_{2} \mathrm{Fe}_{2}(\mathrm{CO})_{n}$ $(n=2,1)$ structures using the BP86 method. Global minima structures are in bold type.

\begin{tabular}{|c|c|c|c|c|c|c|c|c|c|}
\hline \multirow{2}{*}{\multicolumn{2}{|c|}{$\left(\eta^{4}-\mathrm{C}_{4} \mathrm{H}_{6}\right)_{2} \mathrm{Fe}_{2}(\mathrm{CO})_{\mathrm{n}}$}} & & \multirow{2}{*}{$\begin{array}{c}\mathbf{F e}-\mathbf{F e} \\
\text { Distance }\end{array}$} & \multicolumn{2}{|c|}{$\begin{array}{c}\text { Fe Natural } \\
\text { Charge }\end{array}$} & \multicolumn{2}{|c|}{$\begin{array}{c}\text { Fe Electron } \\
\text { Configuration }\end{array}$} & \multirow{2}{*}{$\begin{array}{c}\text { Formal } \\
\text { Bond } \\
\text { Order }\end{array}$} & \multirow{2}{*}{$\begin{array}{c}\text { Wiberg } \\
\text { Bond } \\
\text { Index }\end{array}$} \\
\hline & & & & Fe1 & $\mathrm{Fe} 2$ & Fe1 & $\mathrm{Fe} 2$ & & \\
\hline \multirow[t]{9}{*}{$n=2$} & 2Q-1 & Cs & 2.361 & 0.164 & 0.685 & 17 & 15 & 2 & 0.26 \\
\hline & $2 \mathrm{Q}-2$ & $C_{1}$ & 2.252 & -0.066 & 0.834 & 17 & 15 & 2 & 0.45 \\
\hline & 2Q-3 & $C_{2 h}$ & 2.366 & 0.467 & 0.467 & 16 & 16 & 2 & 0.38 \\
\hline & $2 \mathrm{~T}-1$ & $C_{\mathrm{i}}$ & 2.197 & 0.251 & 0.251 & 17 & 17 & 3 & 0.52 \\
\hline & $2 \mathrm{~T}-2$ & $C_{1}$ & 2.441 & 0.023 & 0.335 & 17 & 17 & 1 & 0.19 \\
\hline & $2 \mathrm{~T}-3$ & $C_{2}$ & 2.267 & 0.157 & 0.157 & 17 & 17 & 3 & 0.52 \\
\hline & $2 \mathrm{~S}-1$ & $C_{1}$ & 2.348 & 0.095 & 0.097 & 18 & 18 & 2 & 0.26 \\
\hline & $2 \mathrm{~S}-2$ & $C_{2 h}$ & 2.332 & 0.121 & 0.121 & 16 & 16 & 2 & 0.59 \\
\hline & $2 S-3$ & $C_{2}$ & 2.337 & 0.206 & 0.206 & 16 & 16 & 2 & 0.93 \\
\hline \multirow[t]{6}{*}{$n=1$} & $1 Q-1$ & $C_{1}$ & 2.252 & 0.187 & 0.742 & 17 & 15 & 3 & 0.52 \\
\hline & 1Q-2 & $C_{1}$ & 2.262 & 0.371 & 0.663 & 16 & 16 & 3 & 0.38 \\
\hline & $1 \mathrm{~T}-1$ & $C s$ & 2.183 & 0.177 & 0.682 & 17 & 15 & 3 & 0.86 \\
\hline & $1 \mathrm{~T}-2$ & $C s$ & 2.108 & 0.194 & 0.503 & 16 & 16 & 3 & 0.81 \\
\hline & $1 \mathrm{~S}-1$ & Cs & 2.051 & 0.131 & 0.467 & 18 & 16 & 4 & 1.30 \\
\hline & 1S-2 & Cs & 2.041 & 0.278 & 0.385 & 18 & 16 & 4 & 1.42 \\
\hline
\end{tabular}

\subsection{Vibrational Frequencies}

Table 8 exhibits the $v(\mathrm{CO})$ frequencies and their infrared intensities for all of the $\left(\mathrm{C}_{4} \mathrm{H}_{6}\right)_{2} \mathrm{Fe}_{2}(\mathrm{CO})_{n}$ $(n=2,1)$ structures, evaluated using the BP86 method, which has been shown to be a reliable predictor of such $v(\mathrm{CO})$ frequencies. The terminal $v(\mathrm{CO})$ frequencies fall in the range from 1908 to $1962 \mathrm{~cm}^{-1}$ whereas the bridging $v(\mathrm{CO})$ frequencies are significantly lower falling in the range from 1761 to $1858 \mathrm{~cm}^{-1}$ (Table 8 ). The significantly lower $v(\mathrm{CO})$ frequencies for bridging relative to terminal carbonyls is well-established and is consistent with the lower effective $\mathrm{C}-\mathrm{O}$ bond order for bridging relative to terminal carbonyl groups in a given type of metal carbonyl structure. 
Table 8. The $v(\mathrm{CO})$ frequencies $\left(\mathrm{cm}^{-1}\right)$ and their infrared intensities $(\mathrm{km} / \mathrm{mol}$, in parentheses $)$ for $\left(\mathrm{C}_{4} \mathrm{H}_{6}\right)_{2} \mathrm{Fe}_{2}(\mathrm{CO})_{n}(n=2,1)$ structures as determined by the BP86 method. Bridging $v(\mathrm{CO})$ frequencies are in bold type.

\begin{tabular}{|c|c|c|}
\hline \multirow[t]{9}{*}{$\left(\mathrm{C}_{4} \mathrm{H}_{6}\right)_{2} \mathrm{Fe}_{2}(\mathrm{CO})_{2}$} & 2S-1 $\left(C_{2 h}\right)$ & $1793(\mathbf{a}, \mathbf{4 9 1}), 1942(\mathrm{a}, 1037)$ \\
\hline & 2S-2 $\left(C_{1}\right)$ & $1761\left(b_{u}, 883\right), 1783\left(a_{g}, 0\right)$ \\
\hline & $\mathbf{2 S - 3}\left(C_{2}\right)$ & 1925 (b, 424), $1955(\mathrm{a}, 1040)$ \\
\hline & $\mathbf{2 T - 1}\left(C_{2}\right)$ & $1842(b, 1078), 1858(a, 65)$ \\
\hline & 2T-2 $\left(C_{1}\right)$ & $1908(\mathrm{a}, 485), 1957(\mathrm{a}, 1296)$ \\
\hline & $\mathbf{2 T}-\mathbf{3}\left(C_{2}\right)$ & $1925(\mathrm{a}, 656), 1950(\mathrm{a}, 1043)$ \\
\hline & 2Q-1 $\left(C_{s}\right)$ & $1815\left(\mathbf{a}^{\prime}, \mathbf{4 5 4}\right), 1962\left(\mathrm{a}^{\prime}, 1045\right)$ \\
\hline & 2Q-2 $\left(C_{1}\right)$ & $1912(\mathrm{a}, 798), 1948(\mathrm{a}, 706)$ \\
\hline & 2Q-3 $\left(C_{2 h}\right)$ & $1842\left(b_{u}, 1002\right), 1858\left(a_{g}, 0\right)$ \\
\hline \multirow[t]{6}{*}{$\left(\mathrm{C}_{4} \mathrm{H}_{6}\right)_{2} \mathrm{Fe}_{2}(\mathrm{CO})$} & $\mathbf{1 S - 1}\left(C_{s}\right)$ & $1933\left(a^{\prime}, 901\right)$ \\
\hline & 1S-2 $\left(C_{s}\right)$ & $1826\left(a^{\prime}, 716\right)$ \\
\hline & $\mathbf{1 T - 1}\left(C_{s}\right)$ & $1929\left(a^{\prime}, 857\right)$ \\
\hline & 1T-2 $\left(C_{s}\right)$ & $1835\left(a^{\prime}, 681\right)$ \\
\hline & 1Q-1 $\left(C_{1}\right)$ & $1925(\mathrm{a}, 870)$ \\
\hline & 1Q-2 $\left(C_{1}\right)$ & $1802(a, 666)$ \\
\hline
\end{tabular}

\subsection{Thermochemistry}

In order to check the potential experimental accessibility of the title compounds, we examined the following energies:

(1) The dissociation energies of carbonyl groups from $\left(\mathrm{C}_{4} \mathrm{H}_{6}\right)_{2} \mathrm{Fe}_{2}(\mathrm{CO})_{2}$, namely:

$$
\left(\mathrm{C}_{4} \mathrm{H}_{6}\right)_{2} \mathrm{Fe}_{2}(\mathrm{CO})_{2} \rightarrow\left(\mathrm{C}_{4} \mathrm{H}_{6}\right)_{2} \mathrm{Fe}_{2}(\mathrm{CO})+\mathrm{CO}
$$

(2) The energies of the following disproportionation reaction:

$$
2\left(\mathrm{C}_{4} \mathrm{H}_{6}\right)_{2} \mathrm{Fe}_{2}(\mathrm{CO})_{2} \rightarrow\left(\mathrm{C}_{4} \mathrm{H}_{6}\right)_{2} \mathrm{Fe}_{2}(\mathrm{CO})_{3}+\left(\mathrm{C}_{4} \mathrm{H}_{6}\right)_{2} \mathrm{Fe}_{2}(\mathrm{CO})
$$

(3) The fragmentation energies of the binuclear $\left(\mathrm{C}_{4} \mathrm{H}_{6}\right)_{2} \mathrm{Fe}_{2}(\mathrm{CO})_{2}$ to mononuclear fragments by the following reaction:

$$
\left(\mathrm{C}_{4} \mathrm{H}_{6}\right)_{2} \mathrm{Fe}_{2}(\mathrm{CO})_{2} \rightarrow 2 \mathrm{C}_{4} \mathrm{H}_{6} \mathrm{Fe}(\mathrm{CO})
$$

Table 9 lists the energies and corresponding free energies for the above reactions taking the energies of the structures $\left(\mathrm{C}_{4} \mathrm{H}_{6}\right)_{2} \mathrm{Fe}_{2}(\mathrm{CO})_{3}$ and $\mathrm{C}_{4} \mathrm{H}_{6} \mathrm{Fe}(\mathrm{CO})$ from ref. [4]. The predicted energy for loss of a single carbonyl group from $\left(\mathrm{C}_{4} \mathrm{H}_{6}\right)_{2} \mathrm{Fe}_{2}(\mathrm{CO})_{2}$ is large, namely $\sim 30 \mathrm{kcal} / \mathrm{mol}$ as well as a free energy of $\sim 20 \mathrm{kcal} / \mathrm{mol}$. The disproportionation of $\left(\mathrm{C}_{4} \mathrm{H}_{6}\right)_{2} \mathrm{Fe}_{2}(\mathrm{CO})_{2}$ to give $\left(\mathrm{C}_{4} \mathrm{H}_{6}\right)_{2} \mathrm{Fe}_{2}(\mathrm{CO})_{3}$ and $\left(\mathrm{C}_{4} \mathrm{H}_{6}\right)_{2} \mathrm{Fe}_{2}(\mathrm{CO})$ using the BP86 method is exothermic, while it is endothermic using M06-L and B3LYP methods by 3.4 and $15.6 \mathrm{kcal} / \mathrm{mol}$, respectively. The corresponding free energies reveal a similar trend. The predicted fragmentation energies of $\left(\mathrm{C}_{4} \mathrm{H}_{6}\right)_{2} \mathrm{Fe}_{2}(\mathrm{CO})_{2}$ to mononuclear $\mathrm{C}_{4} \mathrm{H}_{6} \mathrm{Fe}(\mathrm{CO})$ is significantly larger, namely $\sim 60 \mathrm{kcal} / \mathrm{mol}$ by any of the three methods. 
Table 9. Dissociation energy for removal of one carbonyl group from $\left(\mathrm{C}_{4} \mathrm{H}_{6}\right)_{2} \mathrm{Fe}_{2}(\mathrm{CO})_{2}$, disproportionation energy for $\left(\mathrm{C}_{4} \mathrm{H}_{6}\right)_{2} \mathrm{Fe}_{2}(\mathrm{CO})_{2}$, and dissociation energy for $\left(\mathrm{C}_{4} \mathrm{H}_{6}\right)_{2} \mathrm{Fe}_{2}(\mathrm{CO})_{2} \rightarrow 2 \mathrm{C}_{4} \mathrm{H}_{6} \mathrm{Fe}(\mathrm{CO})$. The corresponding free energies are in italics $(\mathrm{kcal} / \mathrm{mol})$.

\begin{tabular}{ccccc}
\hline & & BP86 & M06-L & B3LYP \\
\hline$\left(\mathrm{C}_{4} \mathrm{H}_{6}\right)_{2} \mathrm{Fe}_{2}(\mathrm{CO})_{2}(\mathbf{2 Q}-\mathbf{1}) \rightarrow\left(\mathrm{C}_{4} \mathrm{H}_{6}\right)_{2} \mathrm{Fe}_{2}(\mathrm{CO})(\mathbf{1 Q}-\mathbf{1})+\mathrm{CO}$ & $\mathrm{E}$ & 34.1 & 33.9 & 30.0 \\
$2\left(\mathrm{C}_{4} \mathrm{H}_{6}\right)_{2} \mathrm{Fe}_{2}(\mathrm{CO})_{2}(\mathbf{2 Q - 1}) \rightarrow\left(\mathrm{C}_{4} \mathrm{H}_{6}\right)_{2} \mathrm{Fe}_{2}(\mathrm{CO})_{3}(\mathbf{3 S}-\mathbf{1})+$ & $\mathrm{G}$ & 22.1 & 22.5 & 15.6 \\
$\left(\mathrm{C}_{4} \mathrm{H}_{6}\right)_{2} \mathrm{Fe}_{2}(\mathrm{CO})(\mathbf{1 Q - 1})$ & $\mathrm{E}$ & -13.9 & 3.4 & 15.6 \\
$\left(\mathrm{C}_{4} \mathrm{H}_{6}\right)_{2} \mathrm{Fe}_{2}(\mathrm{CO})_{2}(\mathbf{2 Q - 1}) \rightarrow 2 \mathrm{C}_{4} \mathrm{H}_{6} \mathrm{Fe}(\mathrm{CO})$ & $\mathrm{G}$ & -10.5 & 9.2 & 18.0 \\
& $\mathrm{E}$ & 59.1 & 73.7 & 59.3 \\
& $\mathrm{G}$ & 46.6 & 62.6 & 47.6 \\
\hline
\end{tabular}

\section{Conclusions}

Unsaturation in binuclear metal carbonyl derivatives can lead to metal-metal multiple bonding, four-electron donor bridging carbonyl groups, and/or metal electronic configurations less than the favorable 18-electron configurations. None of the highly unsaturated $\left(\mathrm{C}_{4} \mathrm{H}_{6}\right)_{2} \mathrm{Fe}_{2}(\mathrm{CO})_{n}(n=2,1)$ structures found in this work has a four-electron donor bridging carbonyl group. Instead the lowest energy $\left(\mathrm{C}_{4} \mathrm{H}_{6}\right)_{2} \mathrm{Fe}_{2}(\mathrm{CO})_{n}(n=2,1)$ structures are perpendicular structures having iron atoms with 15- and 17-electron configurations. This leads to quintet spin states in addition to iron-iron multiple bonds of formal order two for $\left(\mathrm{C}_{4} \mathrm{H}_{6}\right)_{2} \mathrm{Fe}_{2}(\mathrm{CO})_{2}$ and three for $\left(\mathrm{C}_{4} \mathrm{H}_{6}\right)_{2} \mathrm{Fe}_{2}(\mathrm{CO})$. In addition, agostic hydrogen atoms forming $\mathrm{C}-\mathrm{H}$-Fe bridges are seen to be a feature of $\left(\mathrm{C}_{4} \mathrm{H}_{6}\right)_{2} \mathrm{Fe}_{2}(\mathrm{CO})_{n}(n=2,1)$ structures, albeit not the lowest energy such structures. In such structures a butadiene ligand is bonded to one of the iron atoms as a tetrahapto ligand and to the other iron atom through two $\mathrm{C}-\mathrm{H}-\mathrm{Fe}$ units from the end $\mathrm{CH}_{2}$ groups with agostic hydrogen atoms bridging iron-carbon bonds. Singlet $\left(\mathrm{C}_{4} \mathrm{H}_{6}\right)_{2} \mathrm{Fe}_{2}(\mathrm{CO})$ structures with formal $\mathrm{Fe}-\mathrm{Fe}$ quadruple bonds of lengths $\sim 2.05 \AA$ were also found but at very high energies $(\sim 47 \mathrm{kcal} / \mathrm{mol})$ relative to the global minimum.

\section{Acknowledgments}

The research was supported by the Scientific Research Fund of the Key Laboratory of the Education Department of Sichuan Province (Grant No. 10ZX012) and the fund of the Key Laboratory of Advanced Scientific Computation, Xihua University, China, as well as the U. S. National Science Foundation (Grants CHE-0749868 and CHE-0716718).

\section{References}

1. Reihlen, O.; Gruhl, A.; Hessling, G.; Pfrengle, O. Über Carbonyle und Nitrosyle. IV. Liebigs Ann. Chem. 1930, 482, 161-182.

2. Mills, O.S.; Robinson, G. Studies of some Carbon Compounds of the Transition Metals. IV. The Structure of Butadiene Irontricarbonyl. Acta Cryst. 1963, 16, 758-761.

3. Murdoch, H.D.; Weiss, E. Butadien-Eisencarbonyl-Verbindungen. Helvetica Chimica 1962, 45, 1156-1161.

4. Zeng, Y.; Wang, S.J.; Feng, H.; Xie, Y.; King, R.B.; Schaefer, H.F. Open Chains versus Closed Rings: Comparison of Binuclear Butadiene Iron Carbonyls with their Cyclobutadiene Analogues. New J. Chem. 2011, doi:10.1039/c0nj00884b. 
5. Ehlers, A.W.; Frenking, G. Structures and Bond Energies of the Transition Metal Hexacarbonyls $\mathrm{M}(\mathrm{CO})_{6}(\mathrm{M}=\mathrm{Cr}, \mathrm{Mo}, \mathrm{W})$. A Theoretical Study. J. Am. Chem. Soc. 1994, 116, 1514-1520.

6. Delley, B.; Wrinn, M.; Lüthi, H.P. Binding Energies, Molecular Structures, and Vibrational Frequencies of Transition Metal Carbonyls Using Density Functional Theory with Gradient Corrections. J. Chem. Phys. 1994, 100, 5785-5791.

7. Li, J.; Schreckenbach, G.; Ziegler, T. A Reassessment of the First Metal-Carbonyl Dissociation Energy in $\mathrm{M}(\mathrm{CO})_{4}(\mathrm{M}=\mathrm{Ni}, \mathrm{Pd}, \mathrm{Pt}), \mathrm{M}(\mathrm{CO})_{5}(\mathrm{M}=\mathrm{Fe}, \mathrm{Ru}, \mathrm{Os})$, and $\mathrm{M}(\mathrm{CO})_{6}(\mathrm{M}=\mathrm{Cr}, \mathrm{Mo}, \mathrm{W})$ by a Quasirelativistic Density Functional Method. J. Am. Chem. Soc. 1995, 117, 486-494.

8. Jonas, V.; Thiel, W. Theoretical Study of the Vibrational Spectra of the Transition Metal Carbonyls $\mathrm{M}(\mathrm{CO})_{6}[\mathrm{M}=\mathrm{Cr}, \mathrm{Mo}, \mathrm{W}], \mathrm{M}(\mathrm{CO})_{5}[\mathrm{M}=\mathrm{Fe}, \mathrm{Ru}, \mathrm{Os}]$, and $\mathrm{M}(\mathrm{CO})_{4}[\mathrm{M}=\mathrm{Ni}, \mathrm{Pd}$, Pt]. J. Chem. Phys. 1995, 102, 8474-8484.

9. Barckholtz, T.A.; Bursten, B.E. On the Possible Structures of $\mathrm{Mn}_{2}(\mathrm{CO})_{8}$ : Theoretical Support for an Unprecedented Asymmetric Unbridged Isomer. J. Am. Chem. Soc. 1998, 120, 1926-1927.

10 Niu, S.; Hall, M.B. Theoretical Studies on Reactions of Transition-Metal Complexes. Chem. Rev. 2000, 100, 353-406.

11. Macchi, P.; Sironi, A. Chemical Bonding in Transition Metal Carbonyl Clusters: Complementary Analysis of Theoretical and Experimental Electron Densities. Coord. Chem. Rev. 2003, 238-239, 383-412.

12. Carreón-Macedo, J.-L.; Harvey, J.N. Computational Study of the Energetics of ${ }^{3} \mathrm{Fe}(\mathrm{CO})_{4}$, ${ }^{1} \mathrm{Fe}(\mathrm{CO})_{4}$ and ${ }^{1} \mathrm{Fe}(\mathrm{CO})_{4}(\mathrm{~L}), \mathrm{L}=\mathrm{Xe}, \mathrm{CH}_{4}, \mathrm{H}_{2}$ and CO. Phys. Chem. Chem. Phys 2006, 8, 93-100.

13. Bühl, M.; Kabrede, H. Geometries of Transition-Metal Complexes from Density-Functional Theory. J. Chem. Theory Comput. 2006, 2, 1282-1290.

14. Lundberg, M.; Siegbahn, P.E.M.; Morokuma, K. The Mechanism for Isopenicillin N Synthase from Density-Functional Modeling Highlights the Similarities with Other Enzymes in the 2-His-1-carboxylate Family. Biochem. 2008, 47, 1031-1042.

15. Sauriol, F.; Wong, E.; Leung, A.M.H.; Donaghue, I.E.; Baird, M.C.; Wondimagegn, T.; Ziegler, T. Structures and Properties of Nonchelated, $d^{0}$ Alkyl Alkene Complexes of the Type $\left[\mathrm{Cp}_{2} \mathrm{ZrMe}(\text { alkene })\right]^{+}$: Elusive Intermediates during Ziegler-Natta Polymerizations of Alkenes. Angew. Chem. Int. Ed. 2009, 48, 3342-3345.

16. Harvey, J.N.; Jover, J.; Lloyd-Jones, G.C.; Moseley, J.D.; Murray, P.; Renny, J.S. The Newman-Kwart Rearrangement of $O$-Aryl Thiocarbamates: Substantial Reduction in Reaction Temperatures through Palladium Catalysis. Angew. Chem. Int. Ed. 2009, 48, 7612-7615.

17. Sieffert, N.; Bühl, M. Hydrogen Generation from Alcohols Catalyzed by Ruthenium-Triphenylphosphine Complexes: Multiple Reaction Pathways. J. Am. Chem. Soc. 2010, 132, 8056-8070.

18. Hull, J.F.; Balcells, D.; Sauer, E.L.O.; Raynaud, C.; Brudvig, G.W.; Crabtree, R.H.; Eisenstein, O. Manganese Catalysts for $\mathrm{C}-\mathrm{H}$ Activation: An Experimental/Theoretical Study Identifies the Stereoelectronic Factor That Controls the Switch between Hydroxylation and Desaturation Pathways. J. Am. Chem. Soc. 2010, 132, 7605-7616.

19. McNaughton, R.L.; Roemelt, M.; Chin, J.M.; Schrock, R.R.; Neese, F.; Hoffman, B.M. Experimental and Theoretical EPR Study of Jahn-Teller-Active [HIPTN $\left.{ }_{3} \mathrm{~N}\right] \mathrm{MoL}$ Complexes $\left(\mathrm{L}=\mathrm{N}_{2}, \mathrm{CO}, \mathrm{NH}_{3}\right)$. J. Am. Chem. Soc. 2010, 132, 8645-8656. 
20. Feng, X.; Gu, J.; Xie, Y.; King, R.B.; Schaefer, H.F. Homoleptic Carbonyls of the Second-Row Transition Metals: Evaluation of Hartree-Fock and Density Functional Theory Methods. J. Chem. Theor. Comput. 2007, 3, 1580-1587.

21. Zhao, S.; Li, Z.; Wang, W.; Liu, Z.P.; Fan, K.; Xie, Y.; Schaefer, H.F. Is the Uniform Electron Gas Limit Important for Small Ag Clusters? Assessment of Different Density Functionals for $\mathrm{Ag}_{n}$ ( $n \leq 4)$. J. Chem. Phys. 2006, 124, 184102-184111.

22. Becke, A.D. Density-Functional Thermochemistry. III. The Role of Exact Exchange. J. Chem. Phys. 1993, 98, 5648-5652.

23. Lee, C.; Yang, W.; Parr, R.G. Development of the Colle-Salvetti Correlation-Energy Formula into a Functional of the Electron Density. Phys. Rev. B 1988, 37, 785-789.

24. Zhao, Y.; Truhlar, D.G. The M06 Suite of Density Functionals for Main Group Thermochemistry, Thermochemical Kinetics, Noncovalent Interactions, Excited States, and Transition Elements: Two New Functionals and Systematic Testing of Four M06-Class Functionals and 12 Other Functionals. Theor. Chem. Acc. 2008, 120, 215-241.

25. Reiher, M.; Salomon, O.; Hess, B.A. Reparameterization of Hybrid Functionals Based on Energy Differences of States of Different Multiplicity. Theor. Chem. Acc. 2001, 107, 48-55.

26. Dunning, T.H. Gaussian Basis Functions for Use in Molecular Calculations. I. Contraction of (9s5p) Atomic Basis Sets for the First-Row Atoms. J. Chem. Phys. 1970, 53, 2823-2833.

27. Huzinaga, S. Gaussian-Type Functions for Polyatomic Systems. I. J. Chem. Phys. 1965, 42, 1293-1302.

28. Wachters, A.J.H. Gaussian Basis Set for Molecular Wavefunctions Containing Third-Row Atoms. J. Chem. Phys. 1970, 52, 1033-1036.

29. Hood, D.M.; Pitzer, R.M.; Schaefer, H.F. Electronic Structure of Homoleptic Transition Metal Hydrides: $\mathrm{TiH}_{4}, \mathrm{VH}_{4}, \mathrm{CrH}_{4}, \mathrm{MnH}_{4}, \mathrm{FeH}_{4}, \mathrm{CoH}_{4}$, and $\mathrm{NiH}_{4}$. J. Chem. Phys. 1979, 71, 705-712.

30. Frisch, M.J.; Trucks, G.W.; Schlegel, H.B.; Scuseria, G.E.; Robb, M.A.; Cheeseman, J.R.; Scalmani, G.; Barone, V.; Mennucci, B.; Petersson, G.A.; et al. Gaussian09 Program; Gaussian, Inc.: Wallingford, CT, USA, 2009.

31. Reed, A.E.; Curtiss, L.A.; Weinhold, F. Intermolecular Interactions from a Natural Bond Orbital, Donor-Acceptor Viewpoint. Chem. Rev. 1988, 88, 899-926.

\section{Supporting Information}

Tables $\mathrm{S} 1$ to $\mathrm{S} 12$ : Fe-Fe distances $(\AA)$, total energies ( $E$, in hartree), relative energies $(E)$, zero-point energies (ZPE), enthalpies $(\Delta H)$, free energies $(\Delta G$, in $\mathrm{kcal} / \mathrm{mol})$ and numbers of imaginary frequencies (Nimag) for $\left(\mathrm{C}_{4} \mathrm{H}_{6}\right)_{2} \mathrm{Fe}_{2}(\mathrm{CO})_{n}(n=2,1)$ structures at M06-L, BP86 and B3LYP; Tables S13 to S21: Atomic coordinates of the optimized structures for the $\left(\mathrm{C}_{4} \mathrm{H}_{6}\right)_{2} \mathrm{Fe}_{2}(\mathrm{CO})_{2}$ complexes; Tables S22 to S27: Atomic coordinates of the optimized structures for the $\left(\mathrm{C}_{4} \mathrm{H}_{6}\right)_{2} \mathrm{Fe}_{2}(\mathrm{CO})$ complexes; Tables S28 to S36: Harmonic vibrational frequencies (in $\mathrm{cm}^{-1}$ ) and infrared intensities (in parentheses in $\mathrm{km} / \mathrm{mol})$ for the $\left(\mathrm{C}_{4} \mathrm{H}_{6}\right)_{2} \mathrm{Fe}_{2}(\mathrm{CO})_{2}$ complexes; Tables S37 to S42: Harmonic vibrational frequencies (in $\mathrm{cm}^{-1}$ ) and infrared intensities (in parentheses in $\mathrm{km} / \mathrm{mol}$ ) for the $\left(\mathrm{C}_{4} \mathrm{H}_{6}\right)_{2} \mathrm{Fe}_{2}(\mathrm{CO})$ complexes.

(C) 2011 by the authors; licensee MDPI, Basel, Switzerland. This article is an open access article distributed under the terms and conditions of the Creative Commons Attribution license (http://creativecommons.org/licenses/by/3.0/). 